\title{
Prevalence of latex allergy in a population of patients diagnosed with myelomeningocele
}

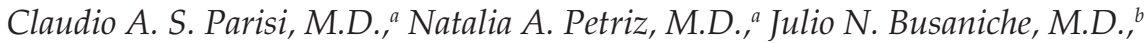 \\ María C. Cortines, M.D., ${ }^{c}$ Fernando A. Frangi, M.D., ${ }^{c}$ Santiago A. Portillo, M.D., \\ and Francisco I. de Badiola, M.D. ${ }^{c}$
}

\begin{abstract}
Introduction: Latex allergy is one of the main reasons of anaphylaxis in the operating room. The prevalence of this condition is higher among patients with myelomeningocele. Epidemiological data obtained from Argentine patients is scarce.

Objective: To estimate the prevalence of latex sensitivity and latex allergy in a population of patients with myelomeningocele and to describe associated risk factors.

Population and Methods: Descriptive, crosssectional, observational study. Family and personal history of allergy, number of surgeries, history of symptoms caused by having been in contactwithlatexorcross-reactivefoods, eosinophil count, measurement of total immunoglobulin E and specificimmunoglobulin Elevels by means of skin and serologic testing for latex, aeroallergens and cross-reactive fruit.

Results: Eighty-two patients diagnosed with myelomeningocele were assessed: 41 were males and their average age was $15.3 \pm 7.66$ years old. Out of all patients, two did not complete skin and serologic testing. Among the remaining 80 patients, $16(19.51 \%)$ had latex allergy, $46(57.5 \%)$ were not allergic, and $18(22 \%)$ showed sensitivity butnotallergy. Having undergone more than five surgeries was a risk factor associated with latex allergy ( $p=0.035)$. No significant association was observed with the remaining outcome measures. Conclusion: According to this study, the prevalence of latex allergy in this population of patients is $19.51 \%$ and the most important risk factor for this condition is a history of having undergone more than five surgeries.

Key words: myelomeningocele, allergy, latex, risk factors, surgery.
\end{abstract}

http:/ /dx.doi.org/10.5546/aap.2016.eng.30

\section{INTRODUCTION}

Latex allergy is an immunoglobulin E ( $\mathrm{IgE}$ )-mediated hypersensitivity reaction that can cause a wide range of symptoms, from mild local manifestations to life-threatening anaphylactic reactions. Latex allergy is one of the main causes of anaphylaxis in the operating room, ${ }^{1-2}$ and prevention of contact with latex in patients belonging to risk groups has demonstrated to significantly reduce their morbidity and mortality. ${ }^{3-4}$

It has been estimated that the prevalence of latex allergy in the general population is lower than $1 \%,{ }_{1}$ but it has been established to be higher in patients with myelomeningocele, ranging between $10 \%$ and $67 \%$, according to different authors. ${ }^{1,4-8}$

Myelomeningocele is a defective closure of the neural tube involving ectodermal and mesodermal structures. The etiology of myelomeningocele is related to multiple factors, possibly influenced by genetic and environmental factors. Patients with myelomeningocele are exposed to latex during the early hours of life as a result of numerous medical and surgical interventions. ${ }^{8}$

This study is the result of the need to collect epidemiological data on the prevalence of latex allergy and associated risk factors in this population of patients.

\section{OBJECTIVE}

To estimate the prevalence of latex sensitivity and allergy in patients attending the Myelomeningocele Clinic of Hospital Italiano de Buenos Aires and to describe associated risk factors.

\section{POPULATION AND METHODS}

Design: Descriptive, cross-sectional and observational study.

Population: All patients diagnosed with myelomeningocele who attended a scheduled appointment at the Myelomeningocele Clinic between May 2006 and May 2013 were assessed.

Exclusion criteria: Patients who refused to participate or to sign the 
informed consent form or who, at the time of the study, had contraindications to have a patch test or use antihistamines, and other situations that may have led to false negative or false positive results according to test performance guidelines. ${ }^{9}$

\section{Outcome measures}

The following outcome measures were assessed:

Age (years).

Sex.

- Family history of allergy: Patients were considered to have a positive family history if they referred having any first-degree relative with asthma, rhinitis, eczema, drug or food allergy. This outcome measure was dichotomized into positive and negative history.

- Personal history of allergy: Patients were considered to have a positive personal history if they referred to have asthma, rhinitis, eczema, drug or food allergy. This outcome measure was dichotomized into positive and negative history. Family and personal history were assessed using specific international questionnaires. ${ }^{10}$

- Number of surgeries: Number of surgeries performed on the patient since birth to the date of the study. This outcome measure was dichotomized into different cut-off points.

- Questionnaire on symptoms caused by contact with latex or cross-reactive foods (fruits or vegetables): This questionnaire was administered to each patient during the allergy assessment visit to establish the presence of symptoms during surgery, on contact with latex-containing elements or after eating cross-reactive foods. Patients were considered positive if they answered yes to some of the questions asked by a specialist. (See the annex).

- Eosinophil count: The absolute eosinophil count was measured based on the blood count to assess the presence or absence of eosinophilia using a Coulter counter.

- Total serum IgE determination: This parameter was measured by means of chemiluminescence (using Beckman Coulter's Dxi 800 system, with dioxetane as a reagent).

- Specific IgE determination: Specific serum IgE levels for latex were obtained from serum samples. It was measured by means of enzyme-linked immunosorbent assay (ELISA) and Capture Assay Radim Liquid Allergens (CARLA).
- Patch testing puncture and immediate reading skin test: The same person performed all skin tests on the volar aspect of the arm. Allergopharma ${ }^{\circledR}$ extracts were used for mites (D. Pternonyssinus, D. Farinae, B. Tropicalis), cockroaches (P. Americana and B. Germanica), $\mathrm{dog}$, cat and fungal epithelia (Alternaria, Penicillium, Aspergillus), tree pollens (plane tree, ash and maple), grass pollens, latex extract, positive control (histamine) and negative control (glycerinated saline solution). Latex glove powder and latex cross-reactive fresh fruits (avocado, kiwi and banana) were also used. The technique used for fresh foods and latex glove powder consisted in piercing the food or extracting powder with a lancet and then use the soaked end of the lancet to prick the patient's skin. A millimeter graduated ruler was used to read the test 20 minutes later, and the measurement corresponding to the average papule diameter was reported in millimeters. The test was considered positive if the average diameter was equal to or higher than $3 \mathrm{~mm}$ from the negative control.

\section{Definitions}

Latex allergy: Patients were considered allergic if they developed immediate hypersensitivity symptoms caused by contact with latex (urticaria, angioedema, generalized erythema, rhinitis, asthma, anaphylaxis) and had positive specific IgE tests (ELISA and/or patch test).

Latex sensitivity: Patients were considered sensitive if they had a positive specific IgE result for latex based on a patch test and/or the ELISA method, but had no symptoms caused by contact with latex.

Eosinophilia: An absolute eosinophil count over $500 / \mathrm{mm}^{3} .^{11}$

Increased total serum IgE: Value above the reference range according to the patient's age at the time of sample collection. ${ }^{12}$

Increased specific IgE: Value above $0.5 \mathrm{kUA} / \mathrm{L}$.

Drug allergy: For those with a history of immediate hypersensitivity symptoms, having two or more reactions following the administration of certain drug, with a subsequent medical assessment and/or specific IgE test for such drug or pharmaceutical compound.

Food allergy: For those with a history of immediate hypersensitivity symptoms, having two or more reactions following the consumption of certain food, with a subsequent medical assessment and/or specific IgE test for such compound. 


\section{Statistical analysis}

Qualitative outcome measures were described using their frequency distribution and the 95\% confidence interval (CI). Quantitative outcome measures were summarized using their mean, standard deviation (SD) or median and interquartile range (IQR) according to their distribution.

A univariate analysis was done using patients allergic to latex as a dependent outcome measure, with all outcome measures. The association between categorical outcome measures and the $\chi^{2}$ test and Fisher's exact test was assessed. The significance level was established at $5 \%(p<0.05)$ in all tests. A multivariate logistic regression analysis was also done including statistically and biologically significant outcome measures.

\section{Ethical aspects}

The study was approved by the hospital's Ethics Committee. All patients and their parents or legal tutors were informed on the nature of the study and were asked to give their informed consent.

\section{RESULTS}

Eighty-two patients were eligible: 41 were males $(50 \%)$ and their average age was $15.3 \pm 7.66$ years old, with a minimum of 1 year old and a maximum of 32 years old. Table 1 describes the results obtained in the study population.

Prevalence of latex allergy and sensitivity: Out of the 82 patients with myelomeningocele, 80 were able to complete the assessment, but neither the patch test nor the ELISA were done in two patients. Among the remaining 80 patients, 16 (19.51\%, 95\% CI: 10.8-28.3) had latex allergy, 46 (57.5\%) were not allergic, and $18(22 \%, 95 \% \mathrm{CI}$ : 12.8-31.1) showed sensitivity but not allergy.

For the univariate analysis, patients allergic to latex were used as dependent outcome measure. No significant association was observed between latex allergy and family or personal history of allergy (asthma, rhinitis, eczema, urticaria, drug allergy, food allergy), positive patch tests for aeroallergens, eosinophilia, or increased total $\operatorname{IgE}(p: \mathrm{ns})$.

Statistical significance was observed between the median number of surgeries performed on patients (Kruskal-Wallis test, $p$ : 0.0011, $13-25-$ 75: 8-18-vs. 8 -25-75: 5-11-) and between the number of surgeries and latex allergy with a logistic regression analysis, even after making an adjustment for age, sex, family history and personal history outcome measures ( $p: 0.0003$, OR 1.55, 95\% CI: 1.22-1.96).

After dichotomizing the number of surgeries, a statistically significant association was found with the presence of allergy based on having had more than five surgeries (Fisher's exact test: 0.0322).

The logistic regression multivariate analysis showed that having had more than five surgeries was a risk factor associated with latex allergy $(p=0.035)$ adjusted for sex and age (OR 1.35, 95\% CI: 1.15-1.58).

\section{DISCUSSION}

In the 1990s, Di Plácido, et al. assessed a group of 27 Argentine children with myelomeningocele and described a $29 \%$ prevalence of hypersensitivity to latex; to this date, this was the only study published in our country. ${ }^{6}$ Our results describe a similar prevalence to that found in other studies published in the international bibliography.

Latex-specific IgE was positive in approximately half of our patients $(42.5 \%)$. Although only $22.5 \%$ have latex sensitivity, in the future they may develop symptoms if no preventive measures are taken. It has been estimated that the risk of anaphylaxis due to latex allergy during a surgery is 500 times higher in the population of patients with myelomeningocele when compared to the general population. ${ }^{7}$

TABLE 1. Description of the study sample of patients with and without latex allergy

\begin{tabular}{lcccc}
\hline Outcome measure & With latex allergy n: 16 (\%) & Without latex allergy n: 64 (\%) & $p$ & All n: 80 (\%) \\
\hline Male & $10(62.5)$ & $31(48.4)$ & ns & $40(50)$ \\
Age (years) Mean & $16.6 \pm 4.6$ & $15.0 \pm 8.3$ & ns & $15.3 \pm 7.66$ \\
Family history of allergy & $12(75.0)$ & $45(70.3)$ & $\mathrm{ns}$ & $57(69.5)$ \\
Number of surgeries & & & & \\
Median (IQR) & $13(8-18)$ & $8(4-11)$ & 0.001 & $8(5-12)$ \\
Increased eosinophil count & $6(37.5)$ & $12(18.7)$ & $\mathrm{ns}$ & $18(21.9)$ \\
\hline
\end{tabular}

IQR: interquartile range; ns: not significant. 
A weakness of this study is that there are no definite data on specificity and sensitivity for the diagnosis of latex allergy using the ELISA method, which is the most commonly used technique in Argentina. Although the results obtained with the CARLA method have demonstrated to be similar to those of other methods used for aeroallergen analysis,$^{13}$ using this technique may have resulted in underdiagnosis. However, such possibility is reduced by the fact that the study included a specialist to perform examinations and patch tests (sensitivity: 67\%-89\%, specificity: $92 \%-96 \%$ ). ${ }^{14}$

Another potential weakness of this study is that it did not include a latex challenge test, which is the gold standard for latex allergy diagnosis; notwithstanding this, performing this test would imply a risk for anaphylaxis and, in general, it is not necessary to make a diagnosis when symptoms are clear and the specific IgE test is positive. ${ }^{15}$

Multiple risk factors for developing latex allergy have been described in this population, including a history of atopy and the number of surgeries. In our study no significant correlation was found between latex allergy and a family or personal history of allergy, a positive patch test for aeroallergens, eosinophilia, or increased IgE. These results contrast those of other studies that found a positive relation. ${ }^{4,6,8}$ Such differences may be due to the number of assessed patients, population characteristics, or associated genetic polymorphisms that are independent from the patient's atopic characteristics. In addition, different authors have stated that spina bifida itself is an independent risk factor for latex allergy. ${ }^{16,17}$

It has been demonstrated that the number of surgeries, especially in the first year of life, is the most important risk factor for sensitization and it is directly related to higher levels of latexspecific IgE. ${ }^{6,16}$

Degenhardt, et al. ${ }^{16}$ assessed 86 patients (mean age: 10.2 years old) with a history of gastrointestinal or urological surgical procedures and found that having more than eight surgeries in the first year of life significantly increased the risk of latex allergy. Studies conducted in adult patients with a condition other than myelomeningocele demonstrated that having more than 10 surgeries was significantly associated with latex allergy $(p<0.001){ }^{17}$

The most significant data obtained from this study is that having more than five surgeries was a risk factor associated with latex allergy in this population. The same number of surgeries was also observed by Michael, et al., who assessed a population of German children with myelomeningocele. ${ }^{18}$

Latex allergy in patients with myelomeningocele appears to be of multifactorial origin, related to a sensitization tendency, exposure and number of surgeries. ${ }^{19}$ Considering results, it is essential to perform a risk assessment in these patients, ${ }^{16,18}$ generate "latex-safe" environments where potentially severe allergic reactions may be prevented, and also highlight that primary prevention protocols in children with myelomeningocele may reduce the frequency of latex sensitization, therefore preventing these children from being exposed to latex since birth. ${ }^{1,4}$

\section{CONCLUSION}

This study demonstrates that there is a high prevalence of latex sensitivity and allergy in this group of patients diagnosed with myelomeningocele, and that a history of more than five surgeries was the most important risk factor for developing this condition.

\section{Acknowledgments}

The authors would like to thank Patricia Evangelista, M.D. and Alejandro Fabián Álvarez, nurse.

\section{REFERENCES}

1. Cabañes N, Igea JM, de la Hoz B, Agustín P, et al. Latex allergy: position paper. I Investig Allergol Clin Immunol 2012;22(5):313-30.

2. Laxenaire MC, Mertes PM. Anaphylaxis during anaesthesia. Results of a two-year survey in France. $\mathrm{Br} \mathrm{J}$ Anaesth 2001;87(4):549-58.

3. Mertes PM, Laxenaire MC. Épidémiologie des reactions anaphylactiques et anaphylactoïdes peranesthésiques en France. Septième enquête multicentrique (Janvier 2001-Décembre 2002). Ann Fr Anesth Reanim 2004;23(12):1133-43.

4. Blumchen K, Bayer P,BuckD, Michael T, et al. Effects of latex avoidance on latex sensitization, atopy and allergic diseases in patients with spina bifida. Allergy 2010;65(12):1585-93.

5. Kinsman SL, Johnston MV. Congenital anomalies of the central nervous system. In Kliegman RM, Stanton BF, St Geme JW, Schor NF, et al, eds. Nelson textbook of Pediatrics. 19th ed. Philadelphia: Elsevier; 2011.Pags.1998-9.

6. Di Plácido P, Corbetta M, Docena G, Fernández R, et al. Prevalencia de hipersensibilidad al látex en pacientes con mielomeningocele. Rev Cir Infant 1997;7(1):36-40.

7. Kelly KJ, Pearson ML, Kurup VP, Havens PL, et al. Acluster of anaphylactic reactions in children with spina bifida during general anesthesia: epidemiologic features, risk factors, and latex hypersensitivity. J Allergy Clin Immunol 1994;94(1):53-61. 
8. Niggemann B, Buck D, Michael T, Wahn U. Latex provocation test in patients with spina bifida: who is at risk of becoming symptomatic? J Allergy Clin Inmunol 1998;102(4 Pt 1):665-70.

9. Heinzerling L, Mari A, Bergman KC, Bresciani M, et al. The skin prick test-European standars. Clin Trasl Allergy 2013;3(1):3.

10. Blaiss MS. Approach to the allergic patient. In: Lieberman $P$, Anderson JA, eds. Allergic diseases. Diagnosis and treatment. Totowa: Humana Press; 1997.Pgs.15-26.

11. Domínguez Ortega J, Reig Rincón de Arellano I, Martinez Alonso JC, Domínguez Ortega C. Evaluación de la eosinofilia. Síndrome eosinofílico y eosinofilias pulmonares. In: Pelaez Hernández A, Dávila González IJ, eds. Tratado de Alergología. Madrid: Ergon;2007:95-111.

12. Vidal C, González Quintela A, Gude F. Evaluación de la elevación de la IgE. In: Pelaez Hernández A, Dávila González IJ, eds. Tratado de Alergología. Madrid: Ergon; 2007.Pgs.81-94.
13. Plebani M, Borghesan F, Bernardi D, Faggian D. Clinical evaluation of a new quantitative method for specific $\operatorname{IgE}$ antibodies. Eur J Clin Chem Clin Biochem 1996;34(7):579-84.

14. Van Kampen V, De Blay F, Folletti I, Kobierski P, et al. EAACI position paper: skin prick testing in the diagnosis of occupational type I allergies. Allergy 2013;68(5):580-4.

15. Parisi CA, Biló B, Bonifazzi F, Bonini S, et al. Alergia al látex. Arch Argent Pediatr 2006;104(6):520-9.

16. DegenhardtP, GollaS, Wahn F, Niggemann B. Latex allergy in pediatric surgery is dependent on repeated operations in the first year of life. J Pediatr Surg 2001;36(10):1535-9.

17. Rueff F, Kienitz A, Schöpf P, Hartl WH, et al. Frequency of natural rubber latex allergy in adults is increased after multiple operative procedures. Allergy 2001;56(9):889-94.

18. Michael T, Niggeman B, Moers A, Seidel U, et al. Risk factors for latex allergy in patients with spina bifida. Clin Exp Allergy 1996;26(8):934-939.

19. Ausili E, Tabacco F, Focarelli B, Nucera E, et al. Prevalence of latex allergy in spina bifida: genetic and environmental risk factors. Eur Rev Med Pharmacol Sci 2007;11(3):149-53. 


\section{Annex}

\section{Questionnaire on symptoms administered by physicians to patients diagnosed with myelomeningocele and their parents}

\section{Questionnaire on symptoms}

Name:

Medical record no.:

Date of birth:

1. Have you ever had allergy symptoms (pruritus, wheals, generalized burning sensation/warmness, persistent nasal congestion) during or after a surgery?

2. Have you ever had skin reactions (pruritic wheals), nasal congestion, difficulty breathing, asthma attacks, in any of the following situations?
a. Contact with rubber gloves
b. During or after a visit to your gynecologist, dentist or a surgery
c. Following contact with condoms
d. While placing a urinary or rectal catheter
e. After blowing up balloons
f. Contact with fruits or vegetables or after eating fruits or vegetables 